\title{
Determinants of reversible contraceptive method discontinuation among women of reproductive age in Kano metropolis, Nigeria
}

\author{
Muktar A. Gadanya, ${ }^{1}$ Fatima E. Aliyu ${ }^{2}$ \\ ${ }^{1}$ Department of Community Medicine, Bayero University/Aminu Kano Teaching Hospital, Kano; \\ ${ }^{2}$ Department of Obstetrics and Gynecology, Aminu Kano Teaching Hospital, Kano, Nigeria
}

\begin{abstract}
Contraceptive discontinuation contributes substantially to the total fertility rate, unwanted pregnancies and induced abortions thereby increasing the already high maternal morbidity and mortality. This study aimed to access contraceptive discontinuation among women of reproductive age in Kano metropolis. Using a cross-sectional study design with concurrent mixed method of data collection, 350 women were studied. Data was collected using a structured interviewer administered questionnaire, focus group discussion and key informant interview guides. Of the 350 participants, 168 of them had discontinued a method of contraception giving a total discontinuation rate was $48 \%$, with method specific discontinuation rate of $35.1 \%$ for implants, $33.9 \%$ for injectables, $21.4 \%$ for pills, and IUD having the lowest rate $(15.5 \%)$. The study
\end{abstract}

Correspondence: Muktar A. Gadanya, Department of Community Medicine, Bayero University/Aminu Kano Teaching Hospital, No. 1 New Hospital Road, Kano, Nigeria.

E-mail: magadanya.cmed@buk.edu.ng

Key words: Reversible contraceptive; discontinuation; women; Kano metropolis.

Conflict of interest: The authors have no conflict of interest to declare.

Availability of data and materials: All data generated or analyzed during this study are included in this published article.

Ethics approval and consent to participate: The Ethics Committee of Kano State Ministry of Health approved this study (MOH/Off/797/B1/1053). The study is conformed with the Helsinki Declaration of 1964, as revised in 2013, concerning human and animal rights. All patients participating in this study signed a written informed consent form for participating in this study.

Informed consent: Written informed consent was obtained from a legally authorized representative(s) for anonymized patient information to be published in this article.

Received for publication: 17 May 2021.

Revision received: 17 June 2021.

Accepted for publication: 17 June 2021.

This work is licensed under a Creative Commons Attribution NonCommercial 4.0 License (CC BY-NC 4.0).

CC Copyright: the Author(s),2021

Licensee PAGEPress, Italy

Annals of African Medical Research 2021; 4:147

doi:10.4081/aamr.2021.147 also found side effects to be the most common reason why women discontinued contraception $(67.1 \%)$, intention to get pregnant (59.5\%), method failure (16.7\%), method switch (12.0\%), and husband's disapproval $(9.5 \%)$. Factors significantly associated with discontinuation at bivariate level were ethnicity, influence on method choice, type of facility where method was obtained, and the type of contraceptive method. These factors were found not to be significant at multivariate level. Contraceptive discontinuation is prevalent in Kano metropolis, meaning that women are at high risk of unintended, mistimed pregnancies, and unsafe abortions, increasing maternal morbidity and mortality. Efforts should be made to tackle the problem of discontinuation through effective educational strategies and counselling techniques.

\section{Introduction}

The rate at which users discontinue a method of contraception is one of the major indicators of quality of use of family planning services. ${ }^{1}$ High discontinuation rates of contraceptives can increase the number of unwanted and high-risk pregnancies, ${ }^{2}$ and because high rates of discontinuation are a major problems for family planning programs, an evaluation of associate factors is necessary. ${ }^{1}$ Studies on contraceptive discontinuation are useful for providers and programs in evaluating family planning program success. ${ }^{3-4}$ Contraceptive discontinuation is defined as "the termination of episodes of use of any reversible contraceptive method which could end up with abandoning use, failure or switch to other method." (pp.1-2). "-6 $^{5-1}$ Prior multi-country research found that discontinuation due to 'reduced need' (an umbrella for issues like "desire to become pregnant, infrequent sex, absence of husband/partner, menopause or sub-fecundity, and marital dissolution/separation") ranged between $7-20 \%$ of users of all reversible methods. ${ }^{7}$

Earlier research on the determinants of contraceptive discontinuation has focused on demographic characteristics and fertility motivations of users, the quality of family planning services or the family planning service environment, and the experience of side effects while using a specific method. Results from this research demonstrate that women who are younger, of higher parity, and unmarried or not in a union are the most likely to discontinue a method. ${ }^{7}$ However, studies have consistently found that the most important factor in discontinuation is the contraceptive method type. ${ }^{6}$ Other demographic factors, such as education, place of residence, and household income, tended to have less consistent relevance for discontinuation. ${ }^{7}$ Fertility desires and other individual-level characteristics of the woman, such as the level of motivation to prevent pregnancies, selfefficacy, and autonomy, are also considered to be directly related to contraceptive discontinuation. Partner involvement in contraceptive discontinuation is not yet well understood, though has been found to be associated with the method choice. ${ }^{7}$ 
This study therefore focused on these key issues. Previous studies of contraceptive method discontinuation and switching, such as those using the cross-sectional Demographic and Health Surveys or the U.S. National Survey of Family Growth, give general estimates, but are limited by imprecise and incomplete data as well as by the poor accuracy of long-term retrospective selfreported contraceptive use data. ${ }^{3}$

The aim of the study is to study the determinants of reversible contraceptive method discontinuation among women of reproductive age in Kano Metropolis, with the following specific objectives.

\section{Materials and Methods}

Kano State is located in North-Western Nigeria, and has an estimated population of women of reproductive age as 3,599,697, 704,108 of which are pregnant every year. Based on the Multiple Indicators Cluster Survey (MICS) of 2017, total fertility rate is $7.7 \%$, the contraceptive prevalence is $6.3 \%$, while unmet need for contraception is $30.8 \%$.

\section{Study design}

The study is a cross-sectional descriptive study with a concurrent mixed method of data collection.

\section{Study population}

The study population comprised of women of reproductive age (15-49 years) from the community in Kano metropolis for the quantitative method study, while the qualitative method study included women of reproductive age, the male partners from the same community, and family planning service providers in Kano metropolis.

\section{Sample size determination}

To determine the minimum sample size, the sample size formula for estimating a single proportion was used:

$\mathrm{n}=\mathrm{Z} 2 \mathrm{pq} / \mathrm{d}^{2}$

Where:

$\mathrm{n}$ is the minimum sample size

$\mathrm{Z}$ is the standard normal deviate corresponding to level of significance of $5 \%=1.96$ (obtained from normal distribution table) $\mathrm{p}$ is the proportion of outcome of interest from a previous study (ex. the discontinuation rate of IUD in Zaria $=0.27)^{8}$

$\mathrm{q}$ is the complementary probability of $\mathrm{p}=1-\mathrm{p}=1-0.27=0.73$

$\mathrm{d}$ is the desired level of precision (usually at $5 \%$ ) $=0.05$

Therefore:

$$
\begin{gathered}
n=\frac{1.96^{2} \times 0.27 \times 0.73}{0.05^{2}} \\
n=315.8
\end{gathered}
$$

$\mathrm{n}=316$

To account for the non-response rate $10 \%$ of the calculated sample size w be added, giving a sample size of 347 , which was approximated to 350 .

\section{Sampling technique}

Quantitative method study: The eight metropolitan local governments were grouped into three based on population density (high, medium, and low population density). One local government was selected randomly from each group comprising of Kano municipal (high density), Nassarawa LGA (medium density), and Kumbotso LGA (low density).

Qualitative method study: For the qualitative data collection, the FGD group participants (females) were selected through a purposive sampling method and each group comprised of women belonging to the same age group, with averagely same number of living children, and same social class to ensure homogeneity. A focused group discussion was conducted with male partners from the same community where the female participants were selected from.

\section{Ethical considerations}

Ethical approval was obtained from the Research Ethics Committee of the state ministry of health. Formal permission was obtained from the primary health care coordinator, traditional heads and facility heads/in charges.

Table 1. Socio-demographic characteristics of respondents.

\begin{tabular}{lc} 
Socio-demographic characteristics & Frequency (\%) n=348 \\
Age (years) & \\
$15-24$ & $32(9.1)$ \\
$25-34$ & $215(61.4)$ \\
$35-49$ & $103(29.4)$ \\
Mean \pm SD & $31.5 \pm 6.3$ \\
Ethnicity & \\
Hausa & $239(68.3)$ \\
Fulani & $66(18.9)$ \\
Yoruba & $26(7.4)$ \\
Igbo & $5(1.4)$ \\
Others & $14(4.0)$ \\
\hline Religion & \\
Islam & $331(94.6)$ \\
Christianity & $19(5.4)$ \\
Occupation & \\
Employed & $159(45.4)$ \\
Unemployed & $191(54.6)$ \\
\hline Highest Level of education & \\
Arabic & $38(10.9)$ \\
Primary & $64(18.3)$ \\
Secondary & $132(37.7)$ \\
Tertiary & $116(33.1)$ \\
Marital Status & \\
Married & $325(92.9)$ \\
Divorced & $14(4.0)$ \\
Widowed & $9(2.6)$ \\
Single & $2(0.6)$ \\
\hline Husband's highest level of education & \\
No formal education & $55(15.7)$ \\
Primary & $11(3.1)$ \\
Secondary & $76(21.7)$ \\
Tertiary & $208(59.4)$ \\
No. of children & \\
1-4 & $218(62.3)$ \\
$\geq 5$ & $132(37.7)$ \\
1-4 & $152(43.4)$ \\
\hline Desired no. of children & \\
$\geq 5$ & \\
\hline & \\
\hline & \\
\hline
\end{tabular}




\section{Results}

A total of 350 respondents were approached for the quantitative component of this study and 348 of the questionnaires were correctly filled and analyzed, giving a response rate of $99.4 \%$. For the qualitative component, 9 FGDs and 3 KIIs were conducted and included in the analysis: 6 FGDs with women and 3 with men, and 3 KIIs with family planning service providers.

\section{Socio-demographic characteristics of respondents}

The age of the respondents ranged from 15 years to 49 years with a mean of 31.56 .3 years. Majority of the women $215(61.4 \%)$ were between 25-34 years and were predominantly Muslims with only about $19(5.4 \%)$ being Christians. Majority of them 239 $(68.3 \%)$ were Hausa by tribe; others included Fulani $66(18.9 \%)$, Yoruba 26 (7.4\%), Igbo 5 (5.4\%).

The overall prevalence of contraceptive discontinuation was $48 \%(n=168)$ of the total 348 respondents. However, the reason specific discontinuation rates were $59.5 \%(n=100)$ because they wanted to get pregnant (intention to get pregnant), 67.1\% (112) due to side effects, $16.7 \%$ (28) due to method failure, $12 \%$ (7) due to method switch, $9.5 \%$ (16) as a result of husband's disapproval, and $5.4 \%$ (9) due to interference with body process.

The table shows that implants had the highest discontinuation rate of $35.1 \%$ with Injectables also having $33.9 \%$ discontinuation rate. IUDs, however has the lowest rate of $15.5 \%$.

Side effects are the most frequent reason why women discontinue contraception (67.1\%), women wanting to get pregnant 59.5\%. Other reasons include method failure (16.7\%), method switch $(7.0 \%)$, husband's disapproval (9.5\%), interference with body process $(5.5 \%)$, with interruption of access, cost, poor quality, and inconvenience having the lowest rate of $(1.2 \%)$ respectively.

Factors associated with contraceptive discontinuation were assessed at bivariate level as shown in Table 4.

To adjust for confounding, these factors that were found to be statistically significant at bivariate level were further subjected to a binary logistic regression. In addition to these, factors that were significant from literature but not significant in this study $(p>0.05)$, and factors with p-value of 0.1 were also included in the model. This is shown in Table 6.

The table showed that all the variables that were significant at the bivariate level were not significant at multivariate level.

Table 7 above shows the behavior of women who discontinued any of the reversible contraceptive method. Of the 168 women who discontinued than two-thirds $125(74.4 \%)$ switched to another method of contraception while $43(25.6 \%)$ abandon method completely.

The table above shows the consequences of contraceptive discontinuation, of the 168 women who discontinued 140 (83.8\%) women became pregnant while 28 (16.7\%) did not.

The table above shows that out of the 140 women who got pregnant following contraceptive discontinuation, $100(71.4 \%)$ had the intention to get pregnant and $40(28.6 \%)$ had an unintended pregnancy.

Table 9 shows the outcome of pregnancy amongst those women who had intention of getting pregnant. 21 (21\%) had spontaneous miscarriage, $75(75 \%)$ had a live birth, and only $4(4 \%)$ of the women had an induced abortion.

Table 11 shows the outcome of pregnancy amongst those women who had an unintended pregnancy $9(22.5 \%)$ had spontaneous miscarriage, $24(60 \%)$ had a live birth, and $7(17.5 \%)$ of the women had an induced abortion.

\section{Discussion}

The study found that contraceptive discontinuation rate was very high in Kano metropolis, which could be a contributor to the high fertility rate, increased rate of unsafe abortion and its complication thereby increasing maternal and child morbidity and mortality. The overall contraceptive discontinuation rate was $48 \%$. This was similar to findings obtained in studies in Bangladesh, Honduras, Brazil, and Colombia. ${ }^{1,8,9}$ Method specific discontinuation rate obtained from this study was found to be $35.1 \%$ for implant. This was found to be lower than was what was found in other studies $(44.0 \%$ and $44.5 \%)$ conducted in northwestern Nigeria and Kenya ${ }^{10,11}$ as against $19.8 \%$ and $15 \%$ that was obtained in northwest Nigeria and Iran. ${ }^{12,13}$ The most probable explanation for these lower rates could be because the studies were hospital-based studies. Injectables had a discontinuation rate of $33.9 \%$ which was similar to what was obtained in Iran (38\%), Uganda, Zimbabwe, Thailand (40\%), ${ }^{12,14}$ but higher than what was found in Indonesia (18\%) and lower than $(67 \%)$ in Dominican Republic and $56.4 \%$ in $\operatorname{Iran}^{1,15}$ due to the large sample size that was obtained from the country's

Table 2. Overall prevalence of contraceptive discontinuation.

\begin{tabular}{|c|c|c|}
\hline $\begin{array}{l}\text { Contraceptive status of } \\
\text { respondents }\end{array}$ & $\begin{array}{l}\text { Frequency } \\
(\mathrm{n}=348)\end{array}$ & Percentage (\%) \\
\hline Still using contraceptive & 180 & 52 \\
\hline Discontinued contraceptive method & 168 & 48 \\
\hline Total & 348 & 100 \\
\hline
\end{tabular}

Table 3. Prevalence of contraceptive discontinuation (method specific discontinuation rate).

\begin{tabular}{lcc} 
Contraceptive method & Frequency & Percentage \\
Pills & 36 & 21.4 \\
Injectables & 57 & 33.9 \\
\hline IUD & 26 & 15.5 \\
Implants & 59 & 35.1 \\
\hline
\end{tabular}

Table 4. Reason specific discontinuation rate of reversible FP method.

\begin{tabular}{lcc} 
Reasons for contraceptive & Frequency & Percentage (\%) \\
discontinuation & 100 & 59.5 \\
Intention to get pregnant & 28 & 16.7 \\
Method failure & 113 & 67.1 \\
\hline Side effects & 12 & 7 \\
\hline Method switch & 16 & 9.5 \\
\hline Husband's disapproval & 9 & 5.4 \\
Interference with body process & 2 & 1.2 \\
\hline Interruption of access & 2 & 1.2 \\
Cost & 2 & 1.2 \\
\hline Poor quality & 2 & 1.2 \\
Inconvenience & 10 & 6 \\
\hline Others & &
\end{tabular}


Table 5. Socio-demographic variables associated with contraceptive discontinuation.

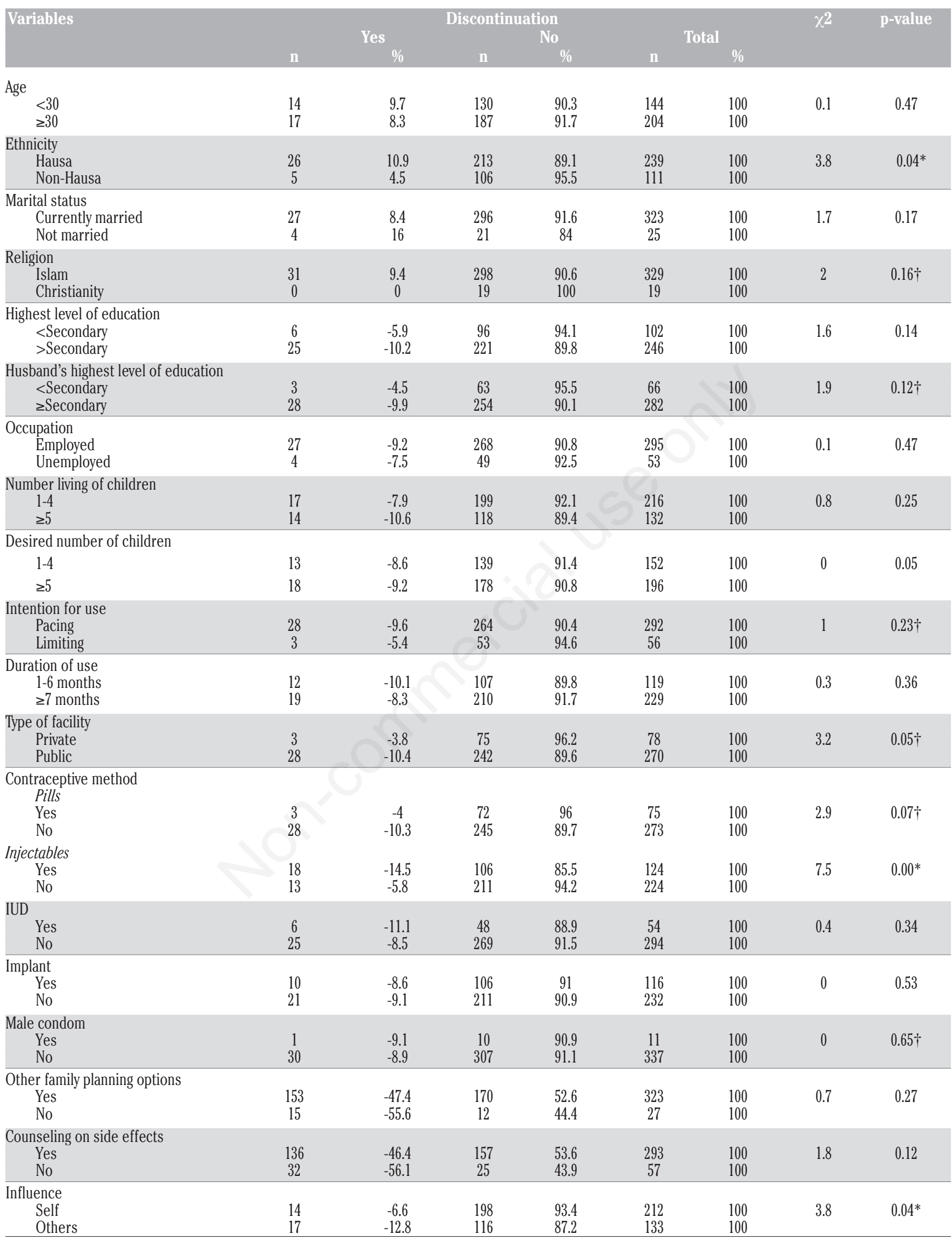

*Significant at p-value $<0.05, \dagger$ Fisher's exact test 
demographic and health surveys. Pills had a total discontinuation rate $21.4 \%$, which was lower than $45-58 \%$ obtained in Armenia, Bangladesh, Colombia, Kenya, Indonesia, and the Dominican Republic. It was also lower than $51.1 \%$ in Honduras ${ }^{15}, 46.3 \%$ in Iran $^{12}, 32.3 \%$ in Uganda, Zimbabwe, Thailand, ${ }^{14} 36 \%$ in Bangladesh $^{16}$ and $69 \%$ in a study conducted amongst French women. These higher rates could be explained by the fact that pills do not require active discontinuation as opposed to IUD or implants that would require a skilled health worker to discontinue. IUD had the lowest rate of $15.5 \%$, this is slightly lower than the discontinuation rates than $22.2 \%$ found in southeast Nigeria, ${ }^{17}$ $22.1 \%$ in Iran, ${ }^{12} 31.3 \%, 34.5 \%, 43 \%$, and $72.1 \%$ in Nepal, India, France, and Honduras respectively. The observed higher rates are due to the fact that IIUDs are not the most preferred contraceptive methods in the study environment due to fear of side effects, the need to undertake minor procedure, social and cultural beliefs attributed to IUDs.

Side effects was the most common reason why women discontinued contraceptive method with a reason specific discontinuation rate of $67.1 \%$ which was higher than what was obtained in a study in southwest Nigeria $17.2 \%$ and $28.3 \%, 8.7 \%$ and $36.1 \%$ in northwest Nigeria, $29 \%$ in Kenya, $40 \%$ in India, $47 \%$ in Bangladesh, $4 \%$ in Brazil, and $55.3 \%$ in Honduras. ${ }^{9-11,15,18-24}$ Desire to have another child was $59.5 \%$ this was similar to what was found in southwest Nigeria $57 \%$ and $61.7 \%,{ }^{18,22} 56 \%$ in India, ${ }^{19}$ which could be because of high fertility rate in developing countries and the cultural beliefs attached to having many children. Although a study in a similar community in northwest showed a discontinuation rate of $13.1 \%$, which could be explain by the fact that the women were predominantly Christians, and 4\% in Brazil, which is a more developed nation than Nigeria, and with a low fertility rate. ${ }^{9,24}$ Method failure constituted $16.7 \%$ as against what was obtained in India $0.9 \%$ and $4.8 \%$ in Honduras, ${ }^{15,20}$ method switch was $12 \%$, higher than $2.1 \%$ found in Kenya ${ }^{10}$ and lower than $27.6 \%$ obtained in a similar community in northwest Nigeria. Husband's disapproval contributed $9.5 \%$ of the discontinuation

Table 6. Multivariate logistic regression by factors associated with discontinuation of reversible contraceptive method.

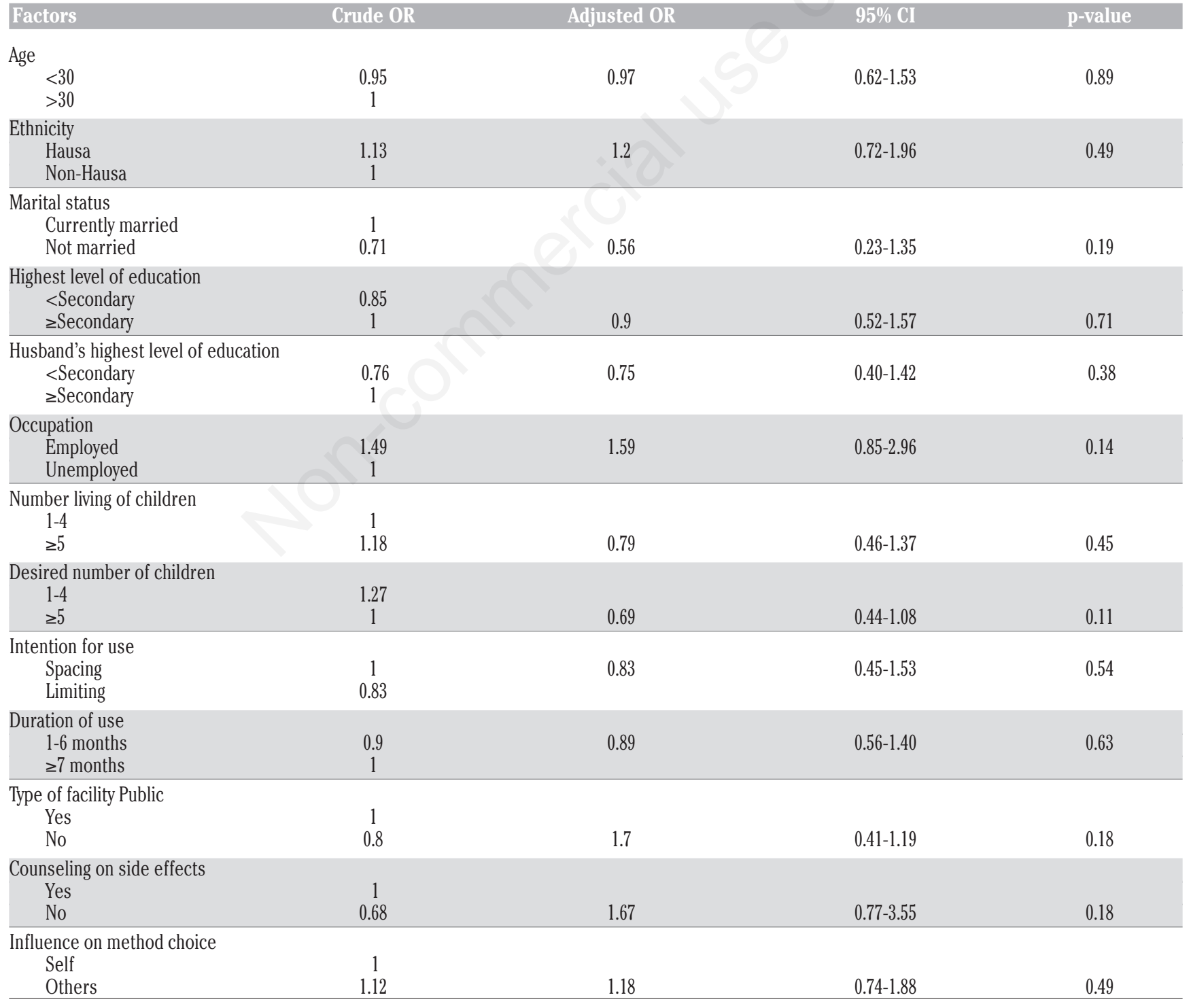

*Significant at p-value $<0.1$ 
rate due to specific reasons which was higher than $4.0 \%$ in northwest Nigeria, $7 \%$ in southwest Nigeria and $1.4 \%$ in Kenya. ${ }^{10,11,18}$ This is because men in these regions are more educated and open to the idea of smaller family size as opposed to men in the northern part of Nigeria. Poor quality service, interference with body process, lack of access all had discontinuation rate of $1.2 \%$ each.

The factors found to be associated with contraceptive discontinuation in this study were ethnicity, type of contraceptive method, and influence on method choice. These were similar to some of the factors associated with contraceptive discontinuation in Ilorin (male partner's support, Influence of friends,

Table 7. Contraceptive behavior following discontinuation.

\begin{tabular}{lc} 
Behavior following discontinuation & Frequency (\%) \\
Abandoned method altogether & $43(25.6)$ \\
Switched to another method & $125(74.4)$ \\
\hline Total & $168(100)$ \\
\hline
\end{tabular}

Table 8. Fertility consequences following contraceptive discontinuation.

\begin{tabular}{lcc}
$\begin{array}{l}\text { Fertility consequences } \\
\text { after discontinuation }\end{array}$ & Number & Percentage (\%) \\
Got pregnant & 140 & $140(83.3)$ \\
Did not get Pregnant & 28 & $28(16.7)$ \\
\hline Total & 168 & 100 \\
\hline
\end{tabular}

Table 9. Pregnancy intention amongst women who discontinued contraception.

\begin{tabular}{lcc} 
Intention to get & Frequency & Percentage (\%) \\
pregnant & 100 & 71.4 \\
Intended & 40 & 28.6 \\
Unintended & 140 & 100 \\
\hline Total &
\end{tabular}

Table 10. Pregnancy outcome (women who intended to get pregnant).

\begin{tabular}{lcc}
\hline Pregnancy outcome & Frequency & Percentage (\%) \\
Miscarriage & 21 & 21 \\
Induced abortion & 4 & 4 \\
\hline Live birth & 75 & 75 \\
Total & 100 & $100(100)$ \\
\hline
\end{tabular}

Table 11. Pregnancy outcome (women who had unintended pregnancy).

\begin{tabular}{lcc} 
Preginancy Outcome & Number & Percentage (\%) \\
Miscarriage & 9 & 22.5 \\
Induced abortion & 7 & 17.5 \\
\hline Live birth & 24 & 60.0 \\
Total & 40 & 100 \\
\hline
\end{tabular}

complication, desired pregnancy), ${ }^{25}$ Ibadan (desire to get pregnant, unpleasant side effects, husband factors, and menopause among IUD users), ${ }^{18}$ Oshogbo (low parity, outcome of antecedent delivery, and intention for use), ${ }^{23}$ Ethiopia (fear of side effects, religious belief, opposition from partner and intention to get pregnant). ${ }^{26}$ In studies conducted in India factors such as preference for a male child, previous contraceptive use, poor mass media exposure, average wealth index and rural residence were found to be associated with higher rate of contraceptive discontinuation but were not considered in this study.

\section{Conclusions}

The total reversible contraceptive discontinuation rate was $48 \%$ suggesting a need to tackle the problem of discontinuation through effective educational strategies and counseling techniques. Factors that were found to be statistically significant to contraceptive discontinuation were ethnicity, type of contraceptive method choice and influence on method choice. The most common reasons for discontinuing a reversible method of contraception were women's desire to conceive and the experience of side effects, with the most common side effects reported as reasons for discontinuation were bleeding, weight changes, and pain. It is therefore crucial to correct the misconceptions and identify the lack of correct and complete information both among the providers and the acceptors to improve the effectiveness of family planning programs.

\section{Recommendations}

There is the need to revise the FP program to strengthen counselling approaches to address fear of side effects, improve followup, and take advantage of missed opportunities to serve women after delivery. There is also the need to develop and implement a mandatory training package on family planning methods and counselling for all relevant health workers, such as physicians, midwives, and social workers. This training package should include other methods that may be added to the current choices. Additionally, community leaders should sensitize members of the community and families on the importance of contraception and consequences of discontinuation.

\section{References}

1. Rakhshani F, Mohammadi M. Contraception continuation rates and reasons for discontinuation in Zahedan, Islamic Republican of Iran. East Mediterr Heal J 2004;10:260-7.

2. Tuladhar H, Marahatta R. Awareness and practice of family planning methods in women attending gyne OPD at Nepal Medical College Teaching Hospital. Nepal Med Coll J 2008;10:184-91.

3. Nanda K, Morrison CS, Kwok C, et al. Discontinuation of oral contraceptives and depot medroxyprogesterone acetate among women with and without HIV in Uganda, Zimbabwe and Thailand. Contraception 2011;83:542-8.

4. Okunlola MA, Owonikoko KM, Roberts OA, Morhason-Bello IO. Discontinuation pattern among IUCD users at the family planning clinic, University College Hospital, Ibadan. J Obstet Gynaecol (Lahore) 2006;26:152-6.

5. Yideta ZS, Mekonen L, Seifu W, Shine S. Contraceptive discontinuation, method switching and associated factors 
among reproductive age women in Jimma town, southwest Ethiopia. Fam Med Med Sci 2017;6:6-11.

6. Bradley SEK, Schwandt H, Khan S. Discontinuation levels, trends, and reasons for contraceptive discontinuation. DHS Anal Stud 2009;20:1-33.

7. Barden-O'Fallon J, Speizer IS, Cálix J, Rodriguez F. Contraceptive discontinuation among Honduran women who use Reversible Methods. Stud Fam Plann. 2011; 42 (1): 11-20.

8. Madugu NH, Abdul MA, Bawa U, Kolawole B. Uptake of hormonal implants contraceptive in Zaria, northern Nigeria. Open J Obstet Gynecol 2015;5:268-73.

9. Moreau C, Bouyer J, Bajos N, et al. Frequency of discontinuation of contraceptive use: results from a French population-based cohort. Hum Reprodution 2018;24:1387-92.

10. Oye-adeniran BA, Adewole IF, Umoh A V, et al. Communitybased study of contraceptive behaviour in Nigeria. Afr J Reprod Health 2006;10:90-104

11. Balogun O, Adeniran A, Fawole A, et al. Effect of male partner's support on spousal modern contraception in a low resource setting. Ethiop J Heal Sci 2016;26:439-48.

12. Austin A. Unmet contraceptive need among married Nigerian women: An examination of trends and drivers. Contraception 2015;91:31-8.

13. Hameed W, Azmat SK, Ali M, et al. Determinants of method switching among social franchise clients who discontinued the use of intrauterine contraceptive device. Int J Reprod Med 2015;2015:1-8.

14. Jain AK, Winfrey W. Contribution of contraceptive discontinuation to unintended births in 36 Developing Countries. Stud Fam Plan 2017;48:269-78.

15. Youssef RM. Contraception use and probability of continuation: community-based survey of women in southern Jordan. East Mediterr Health J 2005;11:545-58.

16. Curtis S, Evens E, Sambisa W. Contraceptive discontinuation and unintended pregnancy: An imperfect relationship. Int
Perspect Sex Reprod Health 2011;32:58-66.

17. Adeyemi AS, Adekanle DA. Progestogen-only injectable contraceptive : Experience of women in Osogbo, southwestern Nigeria. Ann Afr Med 2012;11: 27-31.

18. Fagbamigbe AF, Afolabi RF, Idemudia ES. Demand and unmet needs of contraception among sexually active in-union women in Nigeria: Distribution, associated characteristics, barriers, and program implications. SAGE Open 2018;8:1-11.

19. Agrahari K, Yeo V. Socio-economic differentials in contraceptive discontinuation in India. ARI Work Pap 2014;229:1-22.

20. Thapa S. Early discontinuation of intrauterine device in Nepal - a retrospective study. WHO South East Asia J Public Health 2012;1:309-319.

21. Francis NG. Determinants of discontinuation of five-year implants amongst women of reproductive age in selected health facilities of Nairobi county, Kenya. Thesis, Kenyatta University; 2016.

22. Chigbu B, Onwere S, Aluka C, et al. Contraceptive choices of women in rural southeastern Nigeria. Nigerian J Clin Pract 2010;13:195-9.

23. Isah AY, Nwobodo EI. Family planning practice in a tertiary health institution in North-Western Nigeria. Nigerian J Clin Pract 2009;12:281-3.

24. Pam VC, Mutihir JT, Karshima JA, et al. Factors associated with use and discontinuation of implanon contraceptive in Jos, Nigeria. Trop J Obs Gynaecol 2014;31:90-9.

25. O' Fallen B, Janine LS, Ilene SW, Justine S. Association between contraceptive discontinuation and pregnancy intentions in Guatamala. Pan Am J Public Health 2008;23:4107.

26. Beekle AT, McCabe C. Awareness and determinants of family planning practice in Jimma, Ethiopia. Int Nurs Rev 2006;5:269-78. 